\title{
Mechanisms of Asphalt Blistering on Concrete Bridges*
}

\begin{abstract}
Blistering is a major problem in asphalt-covered concrete structures, such as multi-storage parking buildings, built-up roofs, tunnels, pedestrian areas, or concrete bridge decks. In this particular research, a linear viscoelastic finite-element model is developed to simulate time-dependent blister growth in an asphalt layer under uniformly applied pressure with and without temperature and pressure fluctuation. Indirect tensile tests on mastic asphalt (MA) are performed at three different temperatures to characterize and determine the material properties for the model. A three-dimensional thick-plate axisymmetric finiteelement model is developed using ABAQUS with linear viscoelastic properties and validated with closedform solution from first-order shear-deformation theory for thick plates. Elastic-viscoelastic analogy is used to find an analytic solution for the time-dependent deflection of the blister. In addition, the blister test is conducted on different samples of MA in the laboratory and digital image correlation measurement technique is used to capture the three-dimensional vertical deflection of the MA with time. Finally, the results from image correlation are compared with the finite-element simulation and thick-plate theory analytic solution. The finite-element model simulation shows that the daily temperature variations may have a significant influence on blister growth in asphalt pavements. It is found that the blister can grow continuously under repeated loading conditions over subsequent days. The study concludes that temperature fluctuation in the blister has more influence on blister growth than fluctuation of the pressure inside the blister.
\end{abstract}

KEYWORDS: blister growth, indirect tensile test, finite-element method, master curve, ABAQUS ${ }^{\mathrm{TM}}$, Prony series, sigmoidal function, creep, relaxation, closed-form solution

\section{Introduction}

\section{Elements of a Bridge-Deck System}

The primary aim of waterproofing layers under a bridge-deck pavement is to protect the structural concrete from penetrating water and de-icing chemicals. As shown in Fig. 1, such a waterproofing system often consists of a polymer-modified bitumen membrane (PBM) that is glued to the concrete surface by an adhesive-bonding agent or by welding with a torch. Generally, the bridge-deck pavement consists of two layers of mastic asphalt (MA), composed of aggregate with a maximum aggregate size of $8 \mathrm{~mm}, 11 \mathrm{~mm}$, or $16 \mathrm{~mm}$ and a $6.5 \%$ by weight binder of $20 / 30$ penetration grade to survive extreme traffic conditions [1]. In addition to this, epoxy sealing, acrylate, or polyurethane is used as a waterproofing layer on concrete bridge decks. MA has virtually no air voids. Therefore, it contributes to the waterproofing properties of the system. In general, bituminous waterproofing membranes on bridges have a thickness of $5 \mathrm{~mm}$. They are typically made of styrene-butadiene-styrene polymer-modified bitumen that is carried by glass fiber and polyester fabrics in the center of the sheet. Usually, the upper surface is treated with talcum, sand, and granules for ultraviolet radiation protection. High-quality waterproofing membranes have good thermal stability, flexibility at low temperature, and good adhesion to the concrete surface.

Failure of the adhesive bond between a concrete surface and a waterproofing membrane PBM can occur because of the lack of strength of the concrete or insufficient adhesion and cohesion of the bituminous membrane layer. In addition to this, the welding process can affect the strength of the concrete.

Manuscript received June 12, 2011; accepted for publication November 29, 2011; published online March 2012.

${ }^{1}$ Infrastructure Engineering, Division of Highway and Railway Engineering, School of Architecture and the Built Environment, Royal Institute of Technology (KTH), SE-100 44 Stockholm, Sweden (Corresponding author), e-mail: biruk.hailesilassie@abe.kth.se

${ }^{2}$ Associate Professor, Royal Institute of Technology (KTH), SE-100 44 Stockholm, Sweden; Adjunct Research Professor, Department of Civil and Environmental Engineering, Carleton University, 1125 Colonel By Drive, Ottawa K1S 5B6, Canada; and Director, Road Engineering/Sealing Components, EMPA, Swiss Federal Laboratories for Material Science and Technology, CH8600 Duebendorf, Ueberlandstrasse 129, Switzerland, e-mail: manfred.partl@empa.ch

*Fourth Symposium on Durability of Building and Construction on 16 and 17 June 2011 in Anaheim, CA. 


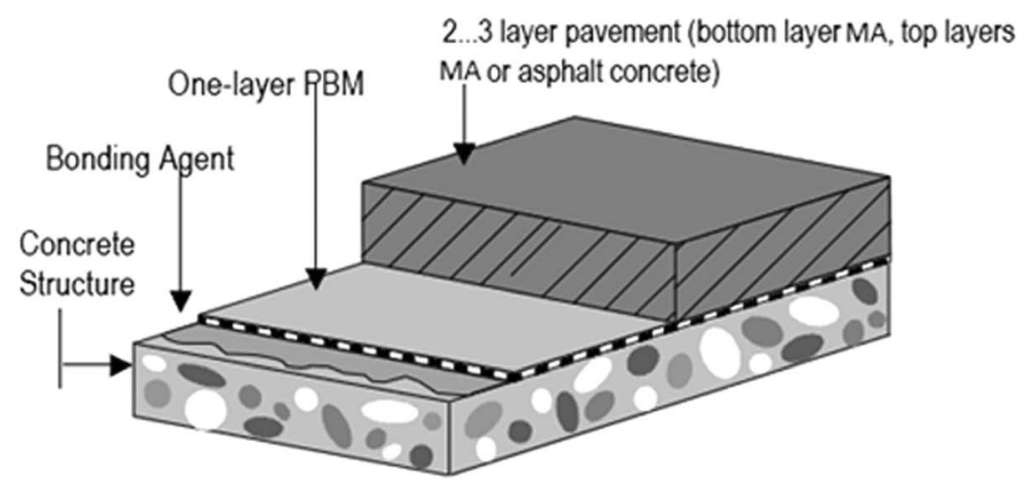

FIG. 1-Scheme of a concrete bridge-deck waterproofing system [2].

Heating can lead to tension in the upper surface followed by cracking or detachment. Various techniques can be used to improve the adhesion, such as sandblasting and water jetting, etc. Possible use of lowviscosity epoxy resin as bonding agent and seal against humidity may be helpful [3].

\section{Reasons for Blister Formation}

Mechanical properties, dimensional change with temperature, permeability, the ability to vent gas, etc., are major issues concerning blistering of waterproofing membranes. The main reason for blister formation is attributed to pressure produced by air and water vapor under the pavement [4]. Blisters can be caused by the expansion of hot, humid air in the concrete after torching of the membrane with an open gas flame.

Short-term blisters occur when placing hot MA and result from humid air trapped in the asphalt mixture. These blisters are often removed in practice by punching a steel stick into the blister of the mixture to release pressure. This bad practice indicates a quality problem either in the material or construction process. Because it is practically impossible to release all pressure by punching through the blisters, some of the smaller blisters may get "frozen" during the cooling process and the trapped air may be the trigger for the formation of long-term blisters that may gradually grow under service condition. Reference 5 suggests that blisters on concrete with asphalt overlay are caused by thermal buckling of the pavement slab.

Waterproofing sheets on roofs may also show blister formation. In a broad analysis of blister phenomena [6], the authors indicate that blisters can only develop in initial voids or unbound areas because of poor membrane application during construction. After such blister initiation, gas expansion inside the blister can cause blisters to grow. When the temperature rises, obviously, the pressure increases. However, from actual pressure measurements within blisters, it was found that the pressure is much lower than calculated for totally entrapped gases [6]. Because of temperature fluctuation in the surrounding environment, air is forced out during daytime and sucked in at night. It is supposed that temperature variation leads to breathing or pumping action, which changes the blister volume.

\section{Objectives}

The primary objective of this study is to develop a finite-element model, which simulates blister growth with focus on long-term blistering. This includes investigation of blister growth in the laboratory with finite-element simulation focusing on blistering of MA and first-order shear-deformation thick-plate theory. It includes also investigating the influence of temperature and pressure fluctuations on blister growth (viscoelastic thick plate) for linearly varying temperature and pressure. In addition to this, a simplified model is established which can simulate blister growth for constant blister radius, considering the viscoelastic properties of the MA, as a basis for future research.

\section{Thick-Plate Theory}

Generally, shell elements are used in models, where the thickness is significantly smaller than other dimensions. Shells with a thickness of more than about $1 / 15$ of the span of the shell are considered as thick 


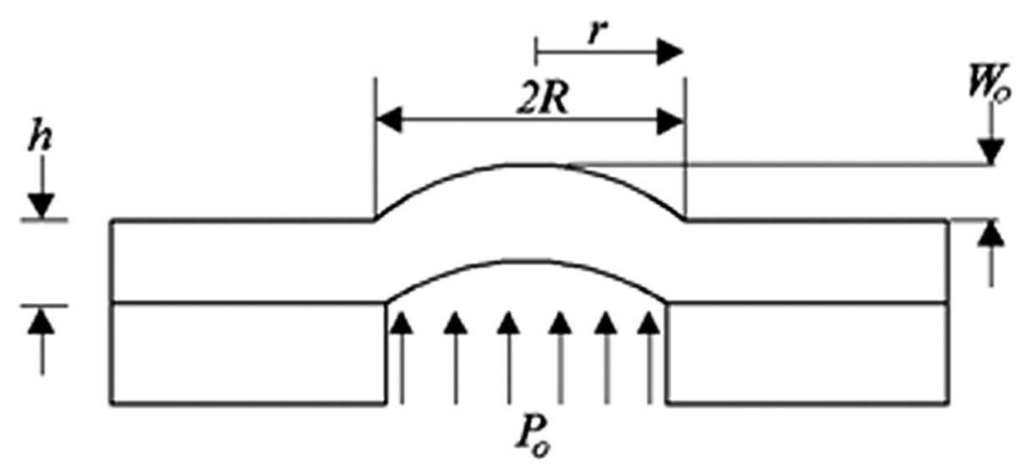

FIG. 2-Scheme of a pressurized blister plate.

shells; otherwise as thin shells [7]. In this report, the exact bending solution from the classical plate theory [8] and the Mindlin plate theories [9] are used. These theories are applied to calculate the out-of-plane displacement-pressure relationship of thin and thick solid isotropic plates, respectively.

In case of thick plates, where the shear deformation is significant, shear-deformation plate theories can be applied. There are numerous shear-deformation plate theories available, the simplest of which is the first-order shear-deformation plate theory (FSDT) also known as the Mindlin plate theory. The deflection equation of the FSDTcan be expressed in terms of the corresponding quantities of the classical plate theory for axisymmetric bending of isotropic circular plates as shown in Eq 1 [9]. A similar equation was used by Fini et al. [10] to calculate the out-of-plane displacement for a thick circular plate (see Fig. 2) under axisymmetric uniform pressure with built-in edge constraint

$$
w_{o}=\frac{p_{o}}{64 D}\left(R^{2}-r^{2}\right)^{2}+\frac{p_{o} R^{2}}{4 S G h}\left(1-\left(\frac{r}{R}\right)^{2}\right)^{2}
$$

where $p_{0}=$ pressure, $r=$ distance from the center of the thick circular plate, $R=$ radius of the thick circular plate, $h=$ thickness of the thick circular plate, $w_{o}=$ displacement at a distance $r$ from the center of thick circular plate, $S=$ shear correction factor ( $5 / 6$ for the thick circular plate), $D=$ flexural rigidity of the plate, $D=E h^{3} /\left[12\left(1-v^{2}\right)\right], G=$ shear modulus of the plate, $G=E /[2(1+v)], E=$ modulus of elasticity, and $\nu=$ Poisson's ratio.

\section{Finite-Element Model: Geometry and Loading}

The bending properties of different meshing elements have been studied with linear elastic analysis and then the dimensions and boundary condition of the viscoelastic model were defined. The continuum threedimensional twenty-node-reduced (C3D20R) element was selected for its good agreement with the linear elastic analytic solution for the vertical deflection of a thick plate. This model had 56 elements and all elements were arranged in a single layer. The linear elastic model for blister formation in a thick plate was used as reference for the viscoelastic finite-element simulation in this chapter.

In this particular case, a three-dimensional (3D) half-circular model was considered. As long as the symmetry conditions hold at the edges, the radial symmetry in the pressurized circular plate allows any size of pie slices or segments to be used in the model. A 3D finite-element model was developed using ABAQUS version 6.8 (SIMULIA Scandinavia Abaqus Scandinavia AB SE-72210 Västerås SWEDEN).

Modeling blister growth in MA has been done by Michalski [11] and blister formation in thermoviscous material was studied by Rogosch [12]. In this paper, a 3D model is established to simulate the time-dependent vertical blister deflection of a thick plate for different types of loading amplitudes.

The geometric finite-element model setup of the 3D plate is shown in Fig. $6(b)$, where the entire contact area between the plate and supporting substrate is constrained in all $\mathrm{df}\left(u_{\mathrm{X}}=u_{\mathrm{Y}}=u_{\mathrm{Z}}=0\right.$, where $u_{\mathrm{X}}$, $u_{\mathrm{Y}}$, and $u_{\mathrm{Z}}$ are displacement in $\mathrm{x}, \mathrm{y}$, and $\mathrm{z}$ axis, respectively, and $u_{\mathrm{RX}}=u_{\mathrm{RY}}=u_{\mathrm{RZ}}=0$, where $u_{\mathrm{RX}}, u_{\mathrm{RY}}$, and $u_{\mathrm{RZ}}$ are rotational displacements in $\mathrm{x}, \mathrm{y}$, and $\mathrm{z}$ axis, respectively). This condition of support represents full adhesion to a rigid substrate beyond the area of the interface. Symmetry plane $\mathrm{x}-\mathrm{z}$ has a degree of freedom $u_{\mathrm{Y}}=0$. A uniform pressure load of $0.03 \mathrm{MPa}$ is applied over the entire region (blister radius) of the 

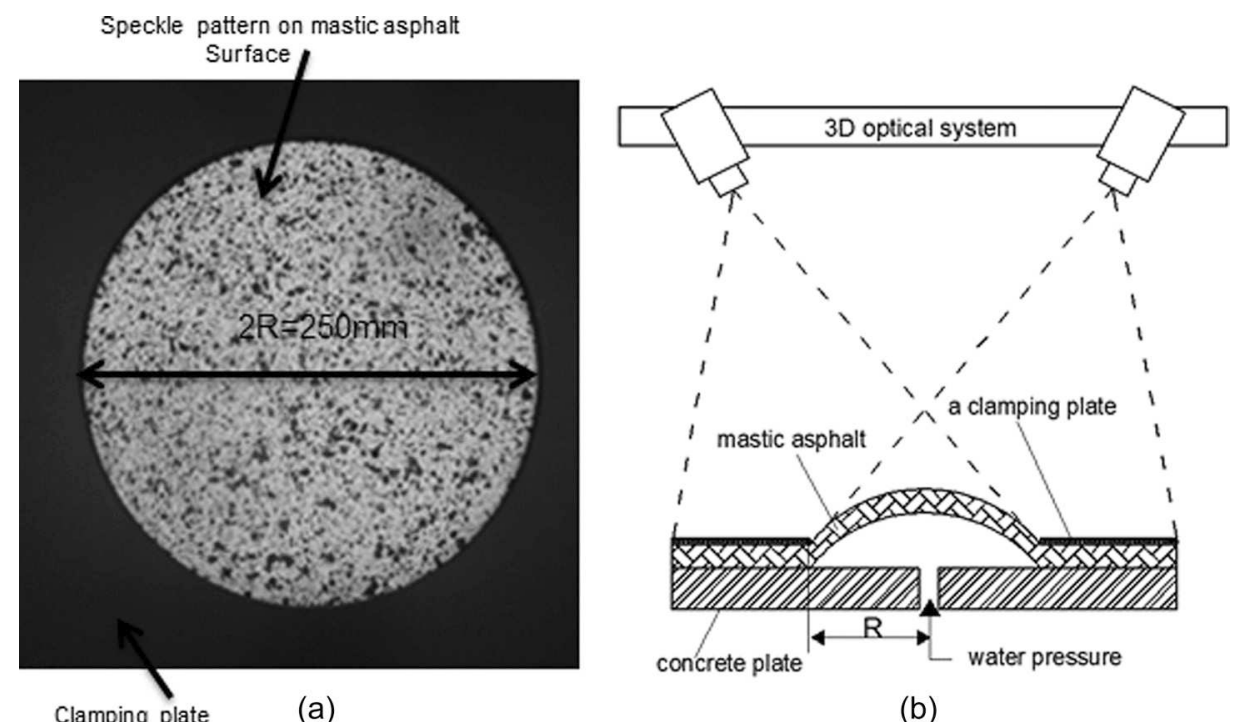

(b)

FIG. 3-(a) Top view of the MA sample after spraying paint to produce speckle image (b) the blister test devise (Vic3D-4Mp).

circular half-plate. The pressure load applied in this model is the same as the pressure used in the laboratory test, which is described below. A constant average temperature of $59^{\circ} \mathrm{C}$ is used in the finite-element simulation model. This temperature is measured during the experiment as mentioned in the next section.

\section{Test Development}

Digital image correlation experiment technique gives the possibility to measure displacement and deformation fields at the surface of objects under any kind of loading condition. The post processing software uses the images taken at different loading times to construct the impression of the distribution of vertical deflection in the measured object. This system can be used in bubble inflation tests to measure the strains on the surface of the bubble [13]. In this case, the blister growth is measured with a 3D digital image correlation system (Limes Vic3D-4Mp) where two cameras were used to measure the out-of-plane deflection of the MA see Fig. 3(b). MA thickness of $25 \mathrm{~mm}$ at temperature of $250{ }^{\circ} \mathrm{C}$ was applied to a concrete plate $500 \times 500 \mathrm{~mm}^{2}$. Because it was intended to study the blister growth caused by bending and stretching of MA, it was important to avoid interfacial fracture between the layer of MA and concrete by keeping the blister radius constant. Therefore, an aluminum clamping plate having a hole with a diameter of $250 \mathrm{~mm}$ was used at the top of the MA, and ordinary white and black paint spray was used to produce a speckle pattern on the surface of the MA, as shown in Fig. 3(a). Water pressure was injected through the concrete plate to produce a pressure for blister growth. The pressure was controlled with a manometer and the pressure was kept constant at $0.03 \mathrm{MPa}$ during the testing period. The temperature inside the blister was recorded using a thermo-element and the average temperature inside the MA was found to be $59^{\circ} \mathrm{C}$. The measured vertical deflection data are presented in Fig. 9 .

\section{Viscoelastic Material Characterization}

Figure 4 describes the steps followed to determine the Prony series parameters as input for the finiteelement model. After performing the creep-compliance test with the indirect tensile test (IDT), the master curve is constructed using a sigmoidal function; then the master curve (experimental data) is fitted to a power-law function. Using this power-law function and Laplace transform, the relaxation modulus in power-law representation is determined and approximated by a four-parameter Prony series as input for the finite-element calculation. Details of the work are shown below.

\section{Creep-Compliance Test}

To predict the blister response accurately, proper characterization of the MA is needed. The viscoelastic properties of MA are measured using either simple creep tests (time domain) or complex modulus tests 


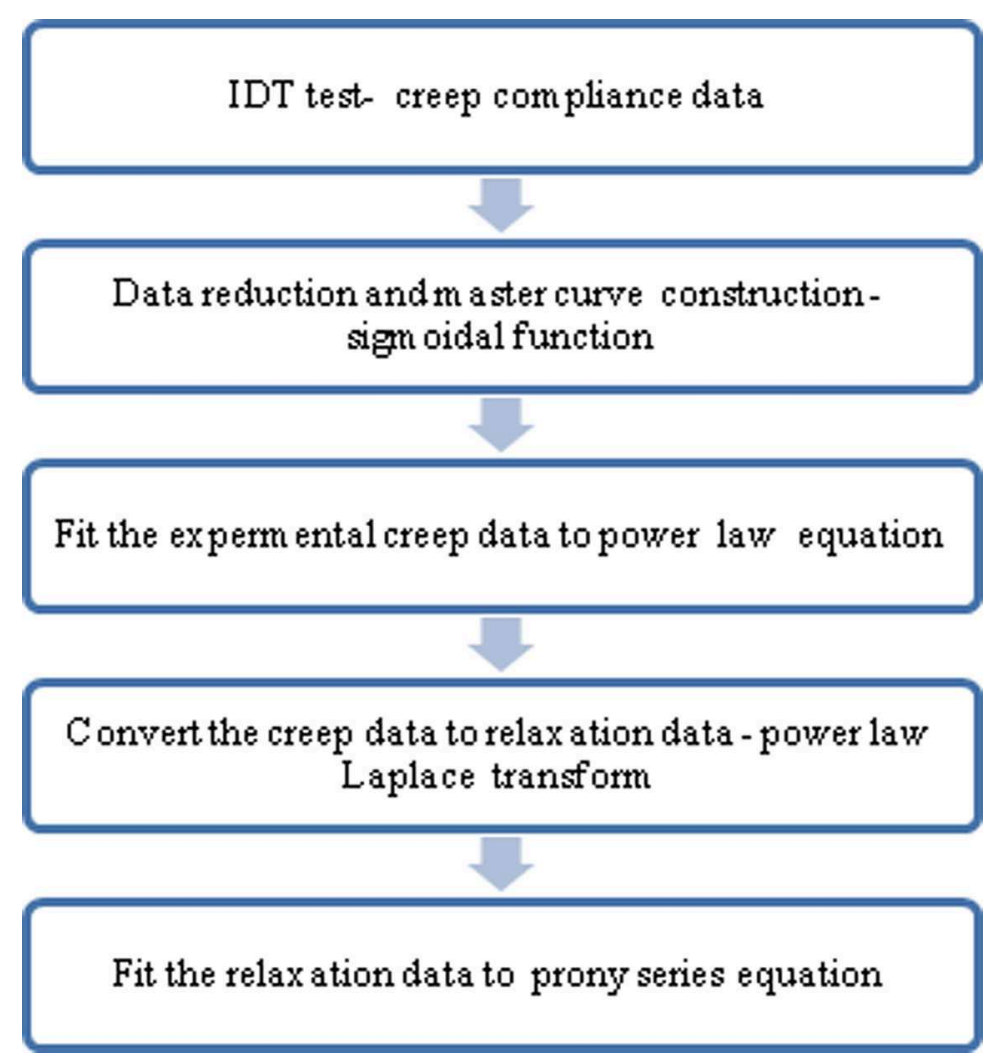

FIG. 4-Scheme of a material characterization for the finite-element model.

(frequency domain). In this study, time domain IDT results are used to describe the viscoelastic properties of the material in $A B A Q U S$. In case of IDTs, a static constant load was applied along the vertical diametrical axis of a temperature-controlled cylindrical specimen for a specified period of time (100 or $1000 \mathrm{~s}$ ), while measuring the horizontal deformation. The load was controlled such that the upper linear-elastic limit of the specimen, typically $100-500 \mu$ str, was not exceeded (see Ref 14 ).

In this report, the dimensions of the indirect tensile specimens were $100 \mathrm{~mm}$ in diameter and $49.8 \mathrm{~mm}$ in height. These specimens were cored from MA slabs. Each specimen was tested at $5^{\circ} \mathrm{C}, 15^{\circ} \mathrm{C}$, and $25^{\circ} \mathrm{C}$ temperatures. A load was applied to cause a horizontal strain in the order of $100 \mu$ str, so that the electric noise during data acquisition process became insignificant. During the loading period, horizontal deformations were measured on both sides of the specimens using four extensometers.

Different theoretical assumptions are commonly used for evaluating IDT results: homogeneity, isotropy, Poisson's ratio, coefficient of thermal contraction, and the estimation of relaxation modulus from the creep compliance are important issues in the IDT analysis [15].

Huang [16] suggested that the Poisson's ratio for most asphalt-mixture ranges between 0.3 and 0.4 . It is stated that it can be appropriate to assume the Poisson's ratio value rather than determining it from actual tests because the effect of Poisson's ratio is not significant. Hence, for simplicity, Poisson's ratio is often assumed to be time independent in spite of the fact that this is not the case in reality [17].

\section{Data Reduction}

In this research, creep compliance is calculated as a function of horizontal deformations. A detailed review of the measurement and analysis system is presented in Ref 18. All correction factors are considered to depend on Poisson's ratio. With this adjustment, the creep compliance was obtained as follows:

$$
D(t)=\frac{\frac{H_{\mathrm{TRIM}}(t)}{L_{G}} \cdot 1.071 \cdot C_{\mathrm{BX}}}{\frac{2 P}{\pi w d}\left(C_{\mathrm{SX}}+3 \nu \cdot C_{\mathrm{SY}}\right)}
$$


TABLE 1-Creep compliance from IDT.

\begin{tabular}{lccc}
\hline & \multicolumn{3}{c}{ Measured creep compliance, $1 / \mathrm{GPa}$} \\
\cline { 2 - 3 } Time, s & $\log (\mathrm{D})$ at $5,{ }^{\circ} \mathrm{C}$ & $\log (\mathrm{D})$ at $15,{ }^{\circ} \mathrm{C}$ & $\log (\mathrm{D})$ at $25,{ }^{\circ} \mathrm{C}$ \\
\hline 1 & $3.70 \cdot 10^{-02}$ & $8.14 \cdot 10^{-01}$ & $6.92 \cdot 10^{0}$ \\
2 & $1.34 \cdot 10^{-01}$ & $7.13 \cdot 10^{-01}$ & $1.53 \cdot 10^{01}$ \\
5 & $2.59 \cdot 10^{-01}$ & $1.57 \cdot 10^{0}$ & $2.35 \cdot 10^{01}$ \\
10 & $4.26 \cdot 10^{-01}$ & $2.19 \cdot 10^{0}$ & $3.73 \cdot 10^{01}$ \\
20 & $7.72 \cdot 10^{-01}$ & $3.79 \cdot 10^{0}$ & $6.07 \cdot 10^{01}$ \\
50 & $1.33 \cdot 10^{0}$ & $6.17 \cdot 10^{0}$ & $8.46 \cdot 10^{01}$ \\
100 & $2.01 \cdot 10^{0}$ & $1.97 \cdot 10^{01}$ & $9.79 \cdot 10^{01}$ \\
200 & $2.91 \cdot 10^{0}$ & $3.22 \cdot 10^{01}$ & $1.21 \cdot 10^{02}$ \\
500 & $4.68 \cdot 10^{0}$ & $5.78 \cdot 10^{01}$ & $1.85 \cdot 10^{02}$ \\
1000 & $6.50 \cdot 10^{0}$ & $8.60 \cdot 10^{01}$ & $2.58 \cdot 10^{02}$ \\
\hline
\end{tabular}

where $D(t)=$ creep compliance, $1 / \mathrm{GPa} ; \nu=$ Poisson's ratio; $P=$ creep load, $\mathrm{N} ; C_{\mathrm{BX}}=$ horizontal bulging correction factor; $C_{\mathrm{SX}}=$ horizontal stress correction factor; $C_{\mathrm{SY}}=$ vertical stress correction factor; $D=$ diameter of the specimen, $\mathrm{mm} ; L_{G}=$ length between gauge point centers, $\mathrm{mm} ; W=$ thickness of the specimen, mm; and $H_{\text {TRIM }}(t)=$ trimmed average horizontal deformation, $\mathrm{mm}$.

The trimmed average horizontal deformation is calculated by ranking each of the horizontal arrays according to their deflection values in considering a window around the middle of the test (46-50 s). After ranking, the horizontal deflection with the highest and the lowest measurement values are removed from the data analysis and four of these results are used out of the six measurements to determine the creep compliance; for details see Ref 18. Creep compliance is calculated with Eq 2. from the row data of IDT for three different temperatures $\left(5^{\circ} \mathrm{C}, 15^{\circ} \mathrm{C}\right.$, and $\left.25^{\circ} \mathrm{C}\right)$ as indicated in Table 1 .

\section{Master Curve Representation}

As shown in Eq 3, the sigmoidal function in combination with the Williams-Landel-Ferry (WLF) equation may be used to construct master curves. Shifting to an arbitrary temperature (in case of this investigation $5^{\circ} \mathrm{C}$ ) is done by solving for the shifting factors with the parameters of the sigmoidal function by leastsquares method.

The different parameters of $\mathrm{Eq} \mathrm{3,} \mathrm{as} \mathrm{determined} \mathrm{from} \mathrm{non-linear} \mathrm{representation} \mathrm{analysis} \mathrm{with}$ the curve-fitting toolbox of Matlab (MathWorks Knarrarnäsgatan 7, Kista Entré, Box SE-16421Kista, SWEDEN), are indicated in Table 2. $R$-square is the square of the correlation between the response values and the predicted response values. The master curve constructed from Eq 3 is shown in Fig. 5(a) and will be used in $A B A Q U S$ to define the thermorheologically simple behavior of the MA

$$
\log (D)=b_{1}+\frac{b_{2}}{1+e^{\left[a_{1}+a_{2}\left(\log (t)+\frac{c_{1}\left(T-T_{\text {ref }}\right)}{c_{2}+\left(T-T_{\text {ref }}\right)}\right)\right]}}
$$

where $D=$ creep compliance, $1 / \mathrm{GPa} ; \quad T=$ time of loading, $\mathrm{s} ; T_{\text {ref }}=$ reference temperature, $\mathrm{K}$; $T=$ temperature, $\mathrm{K} ; b_{1}=$ minimum value of $D ; b_{2}=$ span between maximum and minimum value of $D ; a_{1}$ and $a_{2}=$ parameters describing the shape of the sigmoidal function; $c_{1}$ and $c_{2}=$ WLF constants.

\section{Power-Law Analytical Form of Interconversion}

The power-law analytic form of interconversion is used to predict the relaxation modulus from measured creep-compliance data and as input for characterizing asphalt mixtures in ABAQUS. It is evident that creep

TABLE 2-Sigmoidal parameters and the WLF constants.

\begin{tabular}{lcccccr}
\hline$b_{1}, \mathrm{MPa}$ & $b_{2}, \mathrm{MPa}$ & $a_{1}$ & $a_{2}$ & $c_{1}$ & $c_{2}$ & R-square \\
\hline $3.70 \cdot 10^{-02}$ & $6.98 \cdot 10^{03}$ & 2.097 & -0.908 & 1520 & 11750 & 0.976 \\
\hline
\end{tabular}




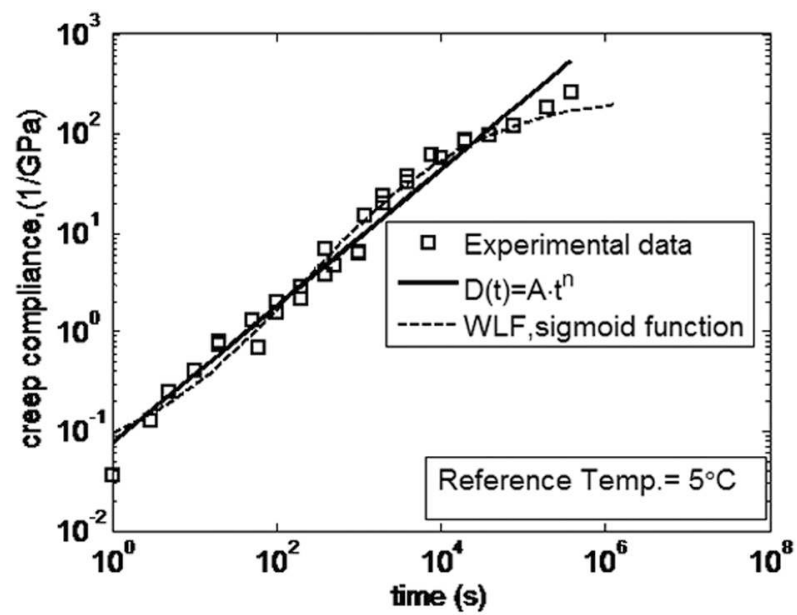

(a)

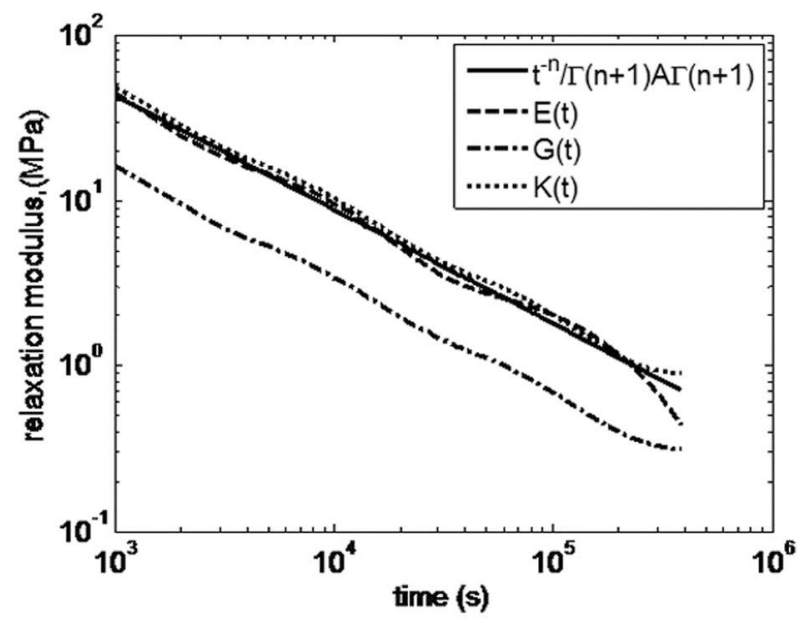

(b)

FIG. 5-(a) Approximation of the creep behavior of MA with a power function, Prony series and master curves for MA at reference temperature $5{ }^{\circ} \mathrm{C}$ (WLF, sigmoid function); (b) shear and bulk relaxation modulus variation with time at $5^{\circ} \mathrm{C}$.

and stress relaxation phenomena are caused by the same linear viscoelastic properties. For linear viscoelastic material, this interconversion can be done by applying Laplace transform

$$
\varepsilon(s)=s D(s) \sigma(s)
$$

where $s$ is the Laplace transform variable, $\varepsilon$ and $\sigma$ are strain and stress, respectively

$$
\sigma(s)=s E(s) \varepsilon(s)
$$

where $E$ is the relaxation modulus. Hence

$$
E(s)=\frac{1}{s^{2} D(s)}
$$

According to Eq 6, the relaxation modulus can be calculated from the creep compliance. Hence, it is easier to express the creep compliance by the power-law function

$$
D(t)=A t^{n}
$$

where $t$ is time and $D(t)$ is creep compliance (1/GPa).

In this report, the experimental creep data are limited to the linear part of the sigmoidal function with maximum slope. Hence, instead of using a sigmoidal function, the data is approximated by a power function for easier interconversion of the creep data to the relaxation modulus. The power-law equation fitted to the creep-compliance data for an arbitrary reference temperature of $5{ }^{\circ} \mathrm{C}$ is expressed by Eq 7 as shown in Fig. 5(a) with, $A=7.71 \cdot 10^{-02} 1 / \mathrm{GPa}$ and $n=6.88 \cdot 10^{-01}$. Transforming Eq 7 into the Laplace domain and substituting into Eq 6 leads to the following Eq 8 after back-transforming the equation into the time domain. The result is shown in Fig. 5(b)

$$
E(t)=t^{-n} \frac{1}{\Gamma(n+1) A \Gamma(n+1)}
$$

where $A$ and $n$ are constants and $\Gamma(n+1)$ is the gamma function.

\section{Relaxation Modulus Determination}

For numerical analysis in $A B A Q U S$, the power-law representation of the relaxation modulus was fitted and replaced by a four-element Prony series according to Eq 9, as shown in Fig. 5(b). The fit with Prony series 


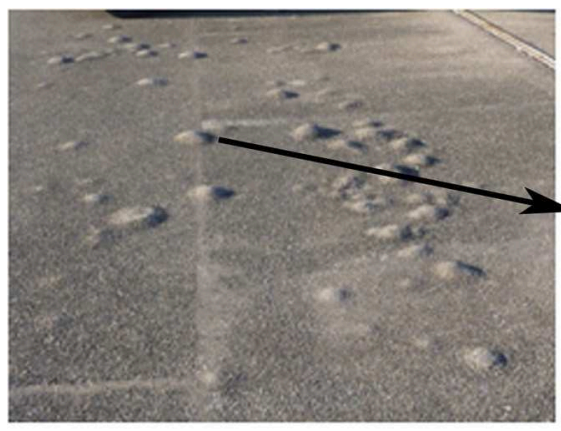

(a)

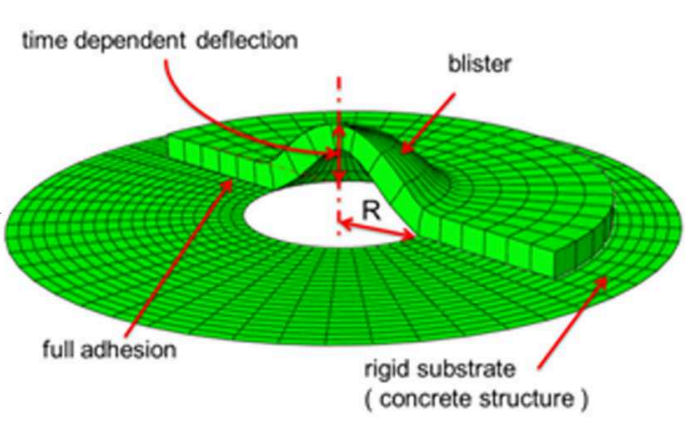

(b)

FIG. 6-(a) Observed blisters, (b) schematic 3D model setup for blister growth simulation.

for a reference temperature of $5{ }^{\circ} \mathrm{C}$ is shown in Fig. 5(b). The fit is not exactly identical to the power-law representation because, for simplicity, only four elements were used. However, for this investigation, four Maxwell elements are considered to be sufficient. The relaxation times of the four Maxwell elements and the Prony series parameters are presented in Table 3

$$
E(t)=\sum_{i=1}^{N+1} E_{i} e^{\frac{-t}{t_{r i}}}
$$

where $E(t)$ is the relaxation modulus, $E_{i}$ are Prony series spring-constant parameters for the relaxation modulus master curve (spring constants or moduli), and $t_{r i}$ are the relaxation times for each Maxwell element.

For 3D multi-axial stress state, it is convenient to describe the stress state with deviatoric and dilatational components. A detailed description is given in Ref 19, a generalized solid Maxwell model is used in $A B A Q U S$ to characterize these two stress-state components. The bulk relaxation modulus follows from Eq 10 and the shear relaxation modulus from Eq 11

$$
\begin{aligned}
& K(t)=K_{0}\left(1-\sum_{i=1}^{n} K_{i}\left(1-e^{\frac{t}{t_{r i}}}\right)\right) \\
& G(t)=G_{0}\left(1-\sum_{i=1}^{n} G_{i}\left(1-e^{\frac{t}{r_{i i}}}\right)\right)
\end{aligned}
$$

where $G$ is shear modulus, $K$ is bulk modulus, $t$ is actual time, $t_{r i}$ are relaxation times, $G_{0}$ and $K_{0}$ are instantaneous shear and bulk elastic moduli, respectively, and $G_{i}$ and $K_{i}$ are Prony series parameters.

Assuming constant Poisson's ratio in the analysis simplifies the problem. This assumption was made in spite of the fact that Poisson's ratio in viscoelastic materials is generally time dependent. The timedependent Poisson's ratio of viscoelastic materials can increase or decrease depending on the bulk and shear relaxation with time [17]. However, because the modeling of blister in this study was assumed to remain in the small strain regime, this simplification was considered acceptable. A time-independent Poisson's ratio of 0.35 was assumed for MA, and introduced in Eqs 12 and 13 to relate time-dependent relaxa-

\begin{tabular}{|c|c|c|c|c|c|c|c|}
\hline \multicolumn{4}{|c|}{ Prony series relaxation time, $\mathrm{s}$} & \multicolumn{4}{|c|}{ Prony series spring constants, $\mathrm{MPa}$} \\
\hline$t r_{1}$ & $t r_{2}$ & $t r_{3}$ & $t r_{4}$ & $E_{1}$ & $E_{2}$ & $E_{3}$ & $E_{4}$ \\
\hline 747.384 & $186.358 \cdot 10^{03}$ & $9.183 \cdot 10^{03}$ & 29.146 & 90.89 & 3.457 & 18.84 & 32.69 \\
\hline
\end{tabular}
tion modulus to the time-dependent bulk and shear relaxation modulus

TABLE 3-Prony series parameters at reference temperature $5{ }^{\circ} \mathrm{C}$. 
TABLE 4-Shear and bulk relaxation modulus Prony series parameters at $5{ }^{\circ} \mathrm{C}$ used for modeling.

\begin{tabular}{llccr}
\hline Instantaneous modulus, MPa & $N$ & $G_{i}, \mathrm{MPa}$ & $K_{i}, \mathrm{MPa}$ & $t_{r i}, \mathrm{~s}$ \\
\hline 79.81 & 1 & 1.605 & 4.757 & 10 \\
& 2 & 42.09 & 39.92 & 44.62 \\
& 3 & 29.21 & 82.91 & 200.60 \\
& 4 & 6.598 & 20.54 & 26874.5 \\
\hline
\end{tabular}

$$
\begin{aligned}
& K(t)=\frac{E(t)}{3(1-2 v)} \\
& G(t)=\frac{E(t)}{2(1+v)}
\end{aligned}
$$

As shown in Fig. 5(b), the power function of the relaxation modules was used for determining the parameters of the Prony series for the generalized Maxwell model by curve fitting. Because the master curve is constructed for the reference temperature of $5{ }^{\circ} \mathrm{C}$, the Prony series parameters represent the time-dependent shear and volumetric behavior of the material at this particular temperature. The Prony series parameters for $25^{\circ} \mathrm{C}$ are determined by shifting the creep compliance data to the reference temperature of $25^{\circ} \mathrm{C}$ and by applying a similar procedure as mentioned above. Table 4 lists the Prony series parameters at $5^{\circ} \mathrm{C}$.

\section{Closed-Form Solution for Viscoelastic Creep}

In any solid body subjected to external loading or displacement, the resulting stress and strain must simultaneously satisfy three basic equations: the equilibrium equations, the kinematic equations, and the constitutive equations. Viscoelastic stress analysis problems are more difficult to solve than elasticity problems because time dependency requires the solution of the differential equations of the constitutive law. If the boundary conditions and the temperature remain invariable, the time variable in the equations can be removed by transforming the equation into the Laplace transform domain as shown earlier.

In this section, the elastic solution shown in Eq 1 is used to determine the deflection of the thick plate. As shown below, for constant Poisson's ratio, Eq 1 is transformed to the equivalent elastic solution with the Laplace domain variable $s$

$$
w_{0}(s)=\frac{3\left(1-v^{2}\right)}{16 s E(s) h^{3}} p(s)\left(R^{2}-r^{2}\right)^{2}+\frac{p(s) R^{2}(1+v)}{2 s E(s) S h}\left(1-\left(\frac{r}{R}\right)^{2}\right)
$$

Rearranging the above expression with Eq 6 results in the following relation

$$
w_{0}(s)=\left(\frac{3\left(1-v^{2}\right)}{16 h^{3}}\left(R^{2}-r^{2}\right)^{2}+\frac{R^{2}(1+v)}{2 S h}\left(1-\left(\frac{r}{R}\right)^{2}\right)\right) p(s) s D(s)
$$

To make the conversion back from the Laplace domain to the time domain, Maple software (Maplesoft, Adept Scientific Nordic, DK-2600 Glostrup, Produktionsvej 26, Sweden) is used. The shear relaxation modulus, the corresponding relaxation times and the Poisson's ratio are used and converted into the creep

TABLE 5-Prony series parameters at reference temperature $5^{\circ} \mathrm{C}$.

\begin{tabular}{lllr}
\hline$D_{0}, \mathrm{MPa}$ & $N$ & \multicolumn{1}{c}{$D_{i}, \mathrm{MPa}$} & \multicolumn{1}{c}{$t_{r i}, \mathrm{~s}$} \\
\hline 0.02729318695 & 1 & $5.68528967271 \cdot 10^{-03}$ & 317.5685434 \\
& 2 & $29.35788435 \cdot 10^{-03}$ & 10.52481012 \\
& 3 & $0.1712212104 \cdot 10^{-03}$ & 19.48316577 \\
& 4 & $29.592292201577 \cdot 10^{-03}$ & 1.935661701 \\
\hline
\end{tabular}


equation, Eq 16. The parameters of Eq 16 are shown in Table 5. The vertical deflection of the thick plate is calculated based on the analytic Eq 17

$$
\begin{gathered}
D(t)=D_{o}+\sum_{i=1}^{N} D_{i}\left(1-e^{\frac{-t}{t_{i}}}\right) \\
w_{0}(t)=\left(\frac{\left(3\left(1-v^{2}\right)\right.}{16 h^{3}}\left(R^{2}-r^{2}\right)^{2}+\frac{R^{2}(1+v)}{2 S h}\left(1-\left(\frac{r}{R}\right)^{2}\right)\right) p_{0} D(t)
\end{gathered}
$$

where $w_{o}$ is vertical deflection of the thick plate $(\mathrm{mm})$.

\section{Temperature and Pressure Influence in Blister Growth}

The thermal environmental conditions have significant impact on stability and long-term performance of a pavement during its life span. Daily temperature variations influence the deformation of asphalt pavement significantly. A linear viscoelastic 3D finite-element model is more realistic than a linear elastic model because it considers time-dependent behavior of the MA and temperature effects on material property. The 3D finiteelement simulation will therefore be used to study blister growth (vertical deflection) of a MA pavement plate subjected to diurnal heating and cooling temperature fluctuation. During daytime of sunny days, heat energy transfer by interaction between pavement and its surroundings exists. This interaction consists of the radiation balance and exchange by convection which comprises solar radiation, thermal radiation heat flux and convection heat flux at the pavement surfaces or at the bottom of the bridge deck [20].

The 3D finite-element model in this study was developed based on the following assumption. The bridge deck pavement lies directly on the bridge deck, i.e., no PBM sheet is applied, the radius of the blister will remain constant, which prohibits horizontal blister growth, i.e., the adhesion between the MA and concrete (rigid substrate) has sufficient strength to prevent debonding. The pavement is idealized as thick plate. The MA is considered to be homogenous, isotropic and linear viscoelastic. The asphalt pavement's temperature fluctuation is the same in the whole cross section of the pavement. The pressure build up inside the blister is only caused by gas pressure; vapor pressure and off-gassing pressures are not considered. The blister cavity is assumed to be closed; therefore, there is no exchange of gas between inside and outside of the blister. The analysis assumes constant Poisson's ratio.

C3D20R Elements were used and one single layer was used to model the blister. Linear quasi-static analysis was used to model time-dependent material response, such as creep and recovery. ABAQUS allows controlling time incrementation automatically or directly by specifying the time. As long as the output results of the simulation are compared with closed form solution, the fixed-time incrementation of $0.8 \mathrm{~s}$ was applied in the analysis. The pressure load applied in this model was estimated from ideal gas law equation, Eq 18

$$
\frac{p_{1} V_{1}}{T_{1}}=\frac{p_{2} V_{2}}{T_{2}}
$$

Where $p_{1}$ and $p_{2}$ are initial pressure $(0.1 \mathrm{MPa}$ at $273.15 \mathrm{~K})$ and the required pressure, respectively, $V_{1}$ and $V_{2}$ are initial volume and final volume of the blister, respectively, and $T_{1}$ and $T_{2}$ are initial temperature $(273.15 \mathrm{~K})$ and final temperature, respectively.

It was assumed that the initial volume is equal to $268.083 \mathrm{~mm}^{3}$ (which corresponds to radius of $800 \mathrm{~mm}$ and blister height $1 \cdot 10^{-04} \mathrm{~mm}$ ) and the final volume is $4.02 \cdot 10^{06} \mathrm{~mm}^{3}$ (for radius of $800 \mathrm{~mm}$ and blister height $1.5 \mathrm{~mm}$ ). The pressures at $5^{\circ} \mathrm{C}$ and $25^{\circ} \mathrm{C}$ are calculated based on the input variables described in Eq 18.

The thick-plate modeling consisted of 80-mm-thick asphalt layer with a constant blister radius of $800 \mathrm{~mm}$. Hence, the ratio of the width to height was $1 / 10$, identical to that of the laboratory-produced blister.

To assess blister growth for $12 \mathrm{~h}$ (1/2 day) under uniformly applied pressure, an initial temperature of $15^{\circ} \mathrm{C}$ was selected at start of the analysis and the temperature of the MA was assumed to increase linearly up to $25^{\circ} \mathrm{C}$ at different rates, as shown in Fig. 7(a). In addition, it was assumed that the temperature inside 


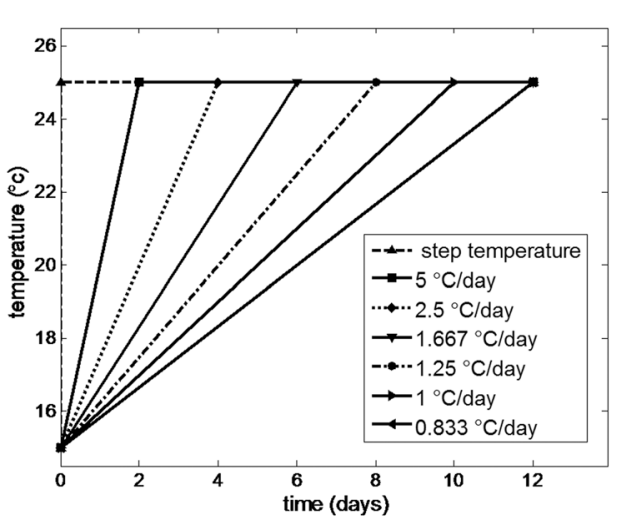

(a)

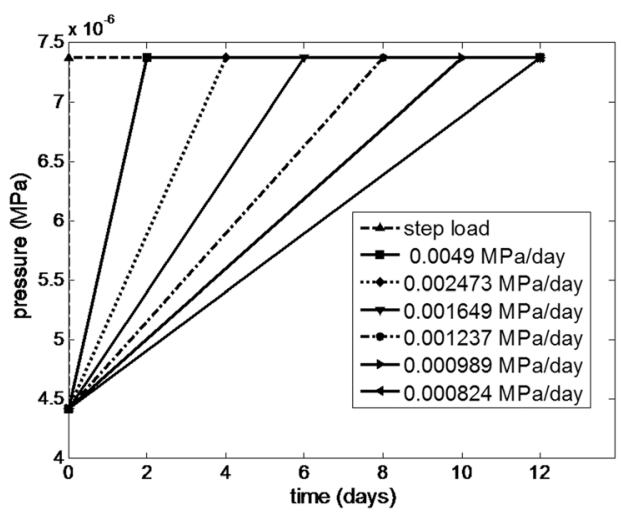

(b)

FIG. 7-(a) Temperature history, and (b) pressure history for different rate (1/2 day).

the blister was rising simultaneously as in the asphalt layer. In this way, gas pressure in the blister corresponded directly to the temperature history as shown in Fig. 7(b).

Moreover, actual temperature measurements on and within the blister, as reported in Ref 21 , are shown in Fig. 8(a). The temperature inside the blister was measured by putting a temperature probe in the MA, whereas the temperature on the surface was measured by fixing the temperature probe using a transparent tape. Because the surface temperature was exposed to air convection it appeared that, the highest temperature was measured inside the blister. These temperature measurements were considered as basis to assess the significance of the daily temperature and pressure variations on the blister growth for one week, a history with repeated temperature and pressure cycles was investigated. For simplicity it was assumed that one cycle consisted of a linear increase within $12 \mathrm{~h}$ and a linear decrease within the following $12 \mathrm{~h}$, as shown in Fig. 8(b). As indicated in the Data Reduction section above, the IDT test is conducted and a master curve for the temperature range between $5{ }^{\circ} \mathrm{C}$ to $25^{\circ} \mathrm{C}$ is determined. Because the MA property is
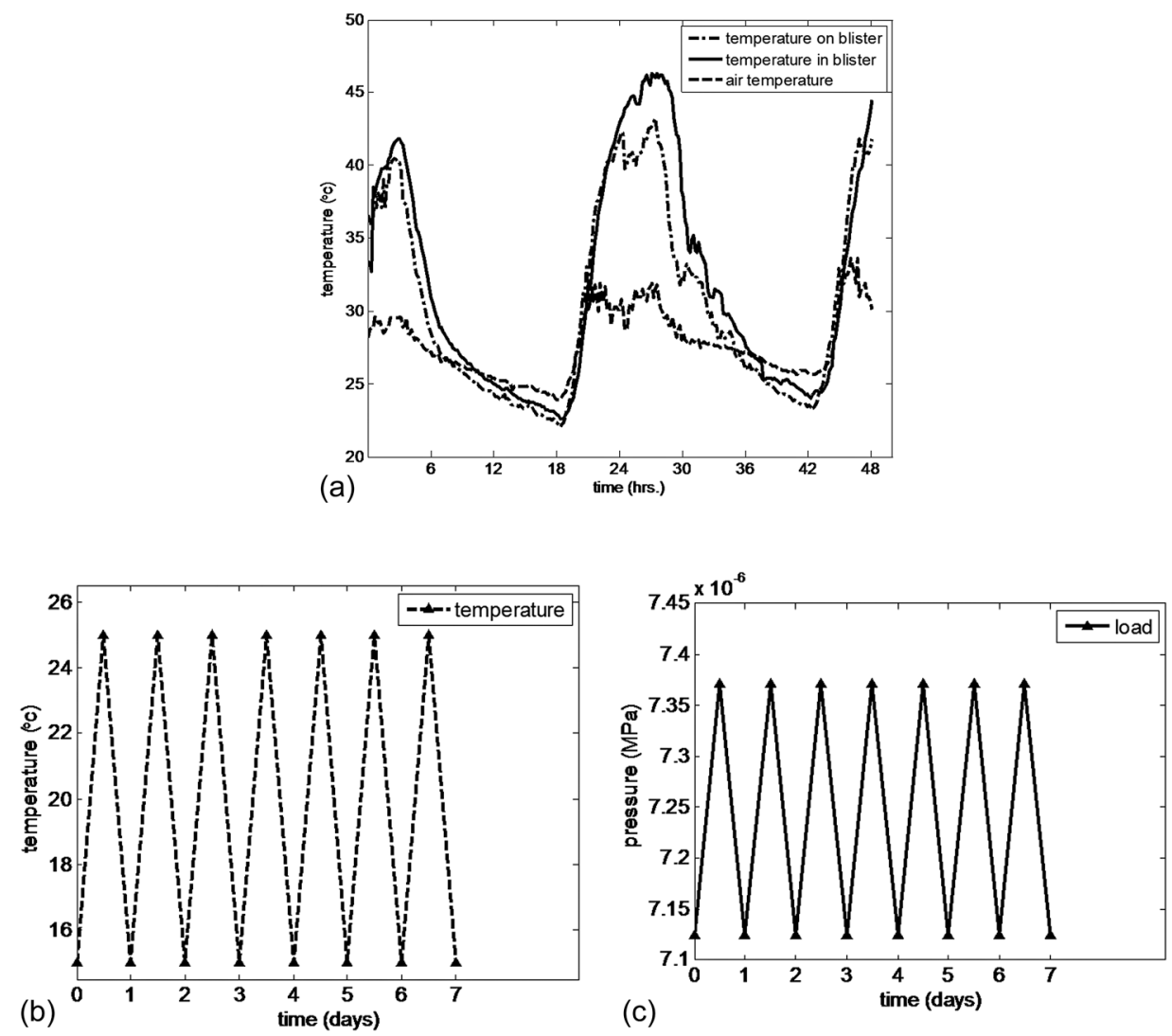

FIG. 8-(a) Temperature measurement in a blister on a bridge deck [21] as compared to idealized (b) temperature, and (c) pressure history (one week) assumed for this study. 
determined for the above specified temperature, the temperature in the finite-element simulation was assumed to vary moderately between $15^{\circ} \mathrm{C}$ and $25^{\circ} \mathrm{C}$. The corresponding pressure history was defined using Eq 18 , in a similar way varying from $7.12 \cdot 10^{-06} \mathrm{MPa}$ to $7.37 \cdot 10^{-06} \mathrm{MPa}$ within one day. This frequency of temperature variation was chosen based on earlier experience [21] in a different case as shown in Fig. 8(b).

\section{Results and Discussion}

Three samples of MA were tested as described in the Test Development section above and the average deflection found from the 3D digital image correlation software profile measurement was compared with the finite-element simulation and the analytic solution as shown in Figs. $9(a)$ and $9(b)$. The standard deviation in Fig. $9(d)$ was calculated from the image correlation measurement by taking different sections on two-dimensional (2D) vertical deflection contour plot shown in Fig. 9(c).

The blister growth estimated with the viscoelastic model produced different deflections depending on the pressure and temperature rate. The pressure and temperature histories from Fig. 7 resulted in vertical

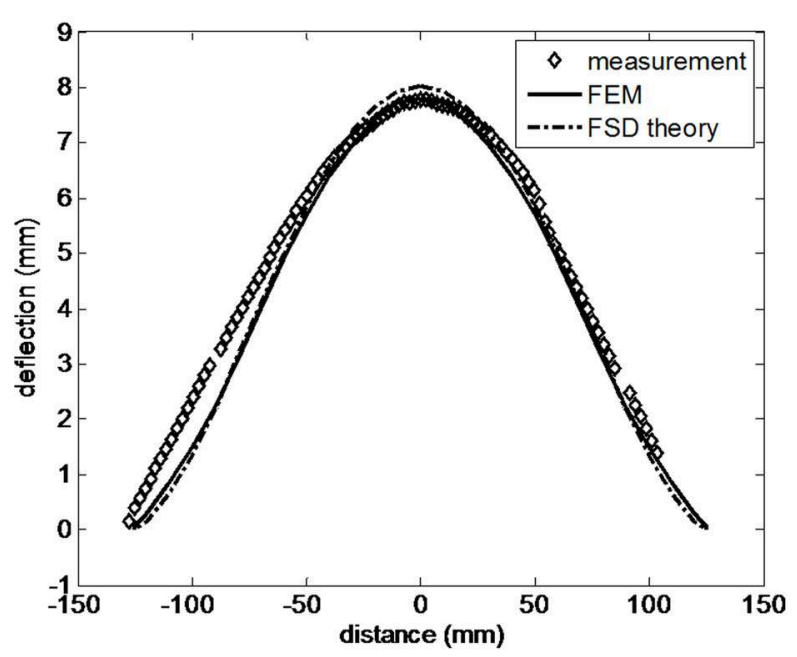

(a)

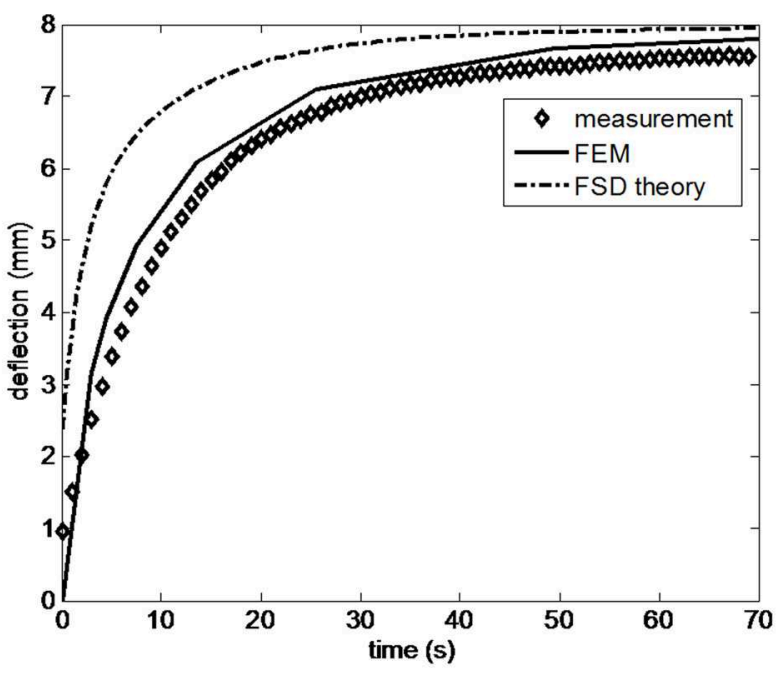

(b)

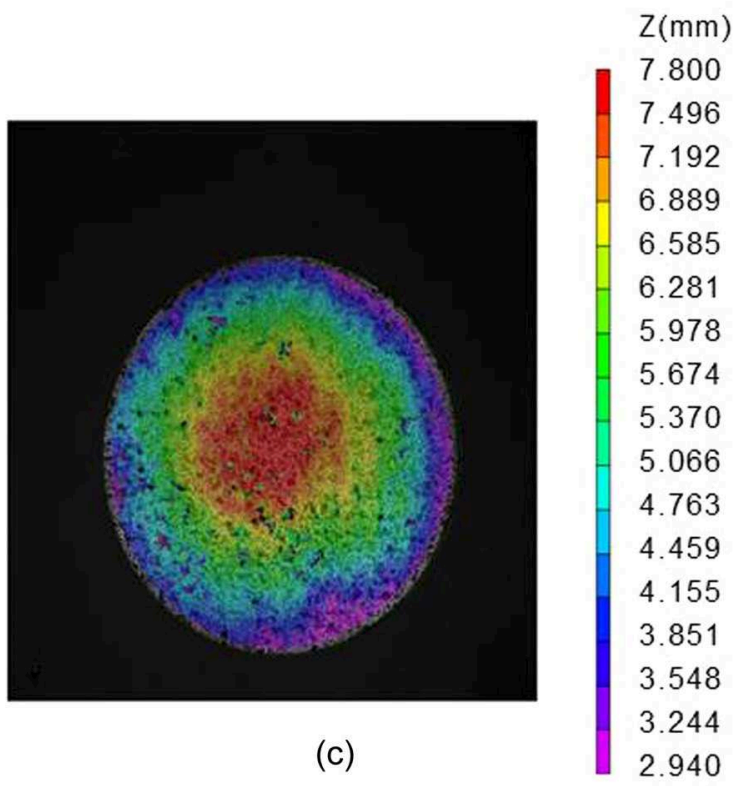

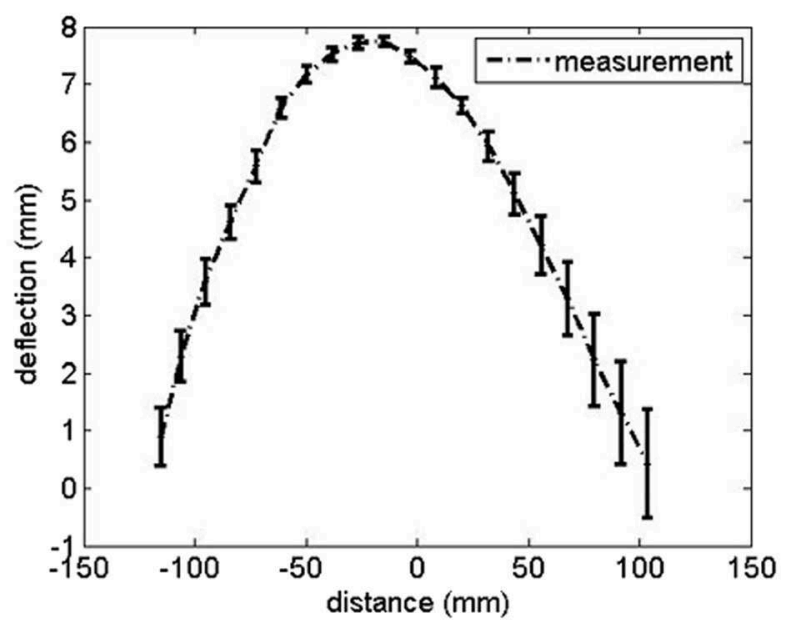

(d)

FIG. 9-Comparison of MA plates with finite element method (FEM) simulation, first-order shear deformation (FSD) plate theory and measurement from image correlation; (a) vertical deflection profile, $(b)$ max vertical defection as a function of time, (c) image correlation $2 D$ plot of vertical deflection after $70 \mathrm{~s}$ of measurement, and (d) vertical deflection with standard deviation. 

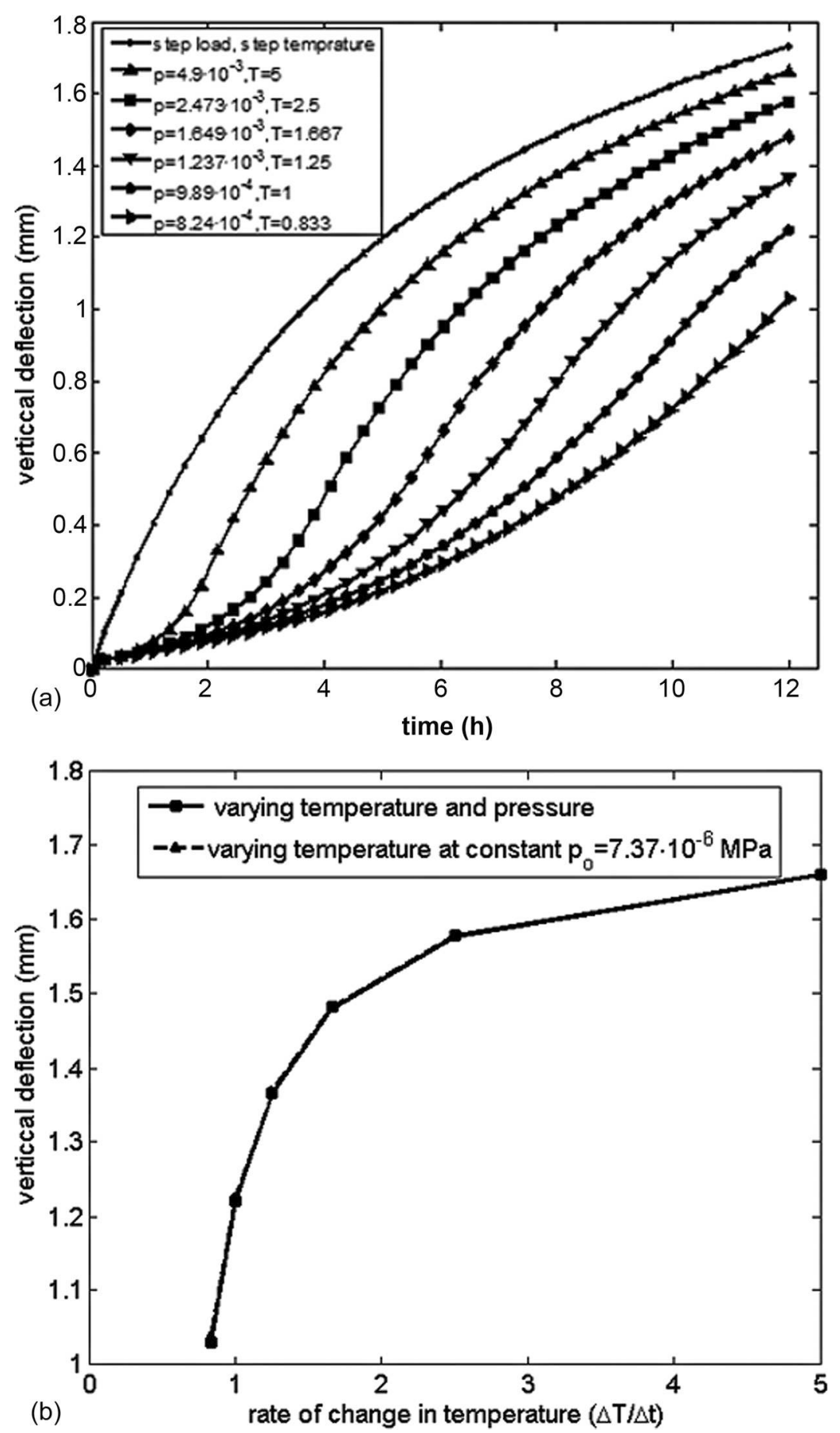

FIG. 10 - (a) Vertical deflection at the center of the plate when both temperature $\left(T,{ }^{\circ} \mathrm{C} /\right.$ day) and pressure $(P, M P a / d a y)$ rate are involved $(12 \mathrm{~h})$, and $(b)$ rate of change in temperature versus vertical deflections at the center of the plate.

deflections shown in Fig. 10(a). The step-function temperature and pressure produced higher vertical deflection $(1.7332 \mathrm{~mm})$ compared to other types of temperature and pressure histories. The minimum vertical deflection was $1.0304 \mathrm{~mm}$.

To assess only the effect of temperature increase in the MA, the temperature histories shown in Fig. 7(a) were applied while keeping the pressure $\left(7.37 \cdot 10^{-06} \mathrm{MPa}\right)$ in the blister constant for $12 \mathrm{~h}$. The result in Fig. 10(b) indicates that temperature increasing rate has significant effect on the deflection of the plate. The entire deflection in the MA was almost completely caused by change in temperature. The deflections found from temperature variation were similar to those from simultaneous temperature and pressure variation as shown in Fig. 10(b). The maximum deflection was $1.7332 \mathrm{~mm}$ for temperature and 


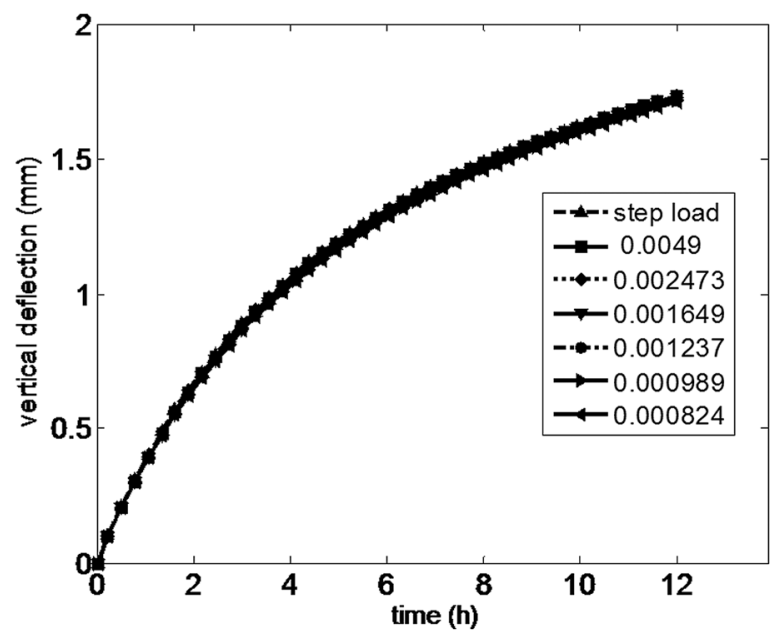

(a)

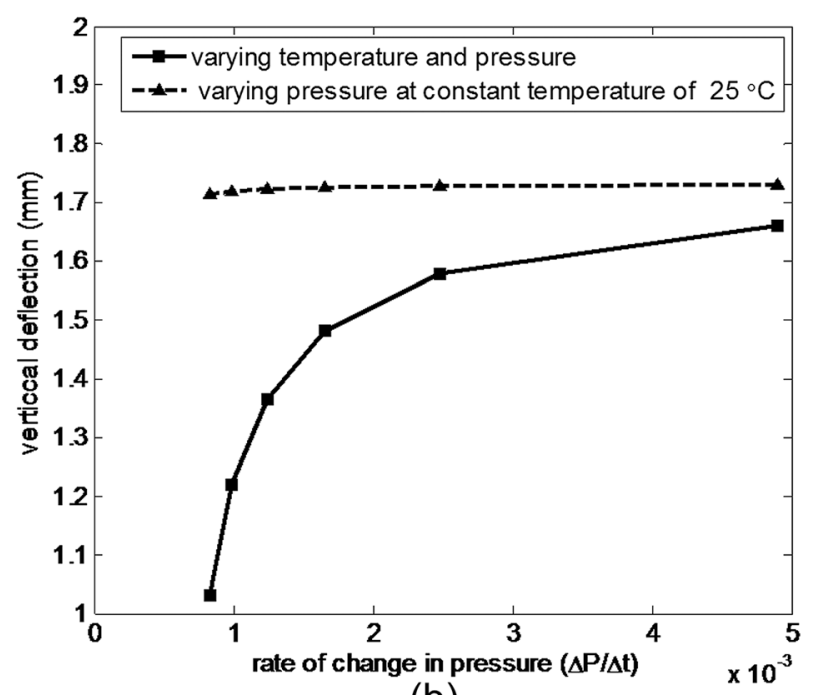

(b)

FIG. 11-(a) Vertical deflection at the center of the plate for different pressure rates (MPa/day) at constant temperature of $25^{\circ} \mathrm{C}(12 \mathrm{~h})$, and $(b)$ rate of change in pressure versus vertical deflections at the center of the plate.

pressure step function and the minimum deflection of $1.0380 \mathrm{~mm}$ was produced by the slowest temperature and pressure rate.

Moreover, the results shown in Fig. 11(a) is found when the temperature was constant throughout the thickness $\left(25^{\circ} \mathrm{C}\right)$ and a linearly varying load history shown in Fig. $7(b)$ was applied. This result shows that the rate at which the pressure increases has no significant influence on the vertical deflection of the MA. The deflection found from pressure variation is clearly different to the deflection from simultaneous variation of temperature and pressure as shown in Fig. 11(b). The maximum vertical deflection obtained was $1.7332 \mathrm{~mm}$ and the minimum vertical deflection was $1.7148 \mathrm{~mm}$.

In Fig. 12 the vertical deflection from pressure and temperature fluctuation in one week is presented. The highest deflection of $1.2877 \mathrm{~mm}$ was found for repeated simultaneously varied temperature and pressure. In case of fluctuating temperature and constant pressure $\left(7.124 \cdot 10^{-06} \mathrm{MPa}\right.$ corresponding to a temperature of $15^{\circ} \mathrm{C}$ ), a vertical deflection of $1.2228 \mathrm{~mm}$ was found. Pressure fluctuation had no significant

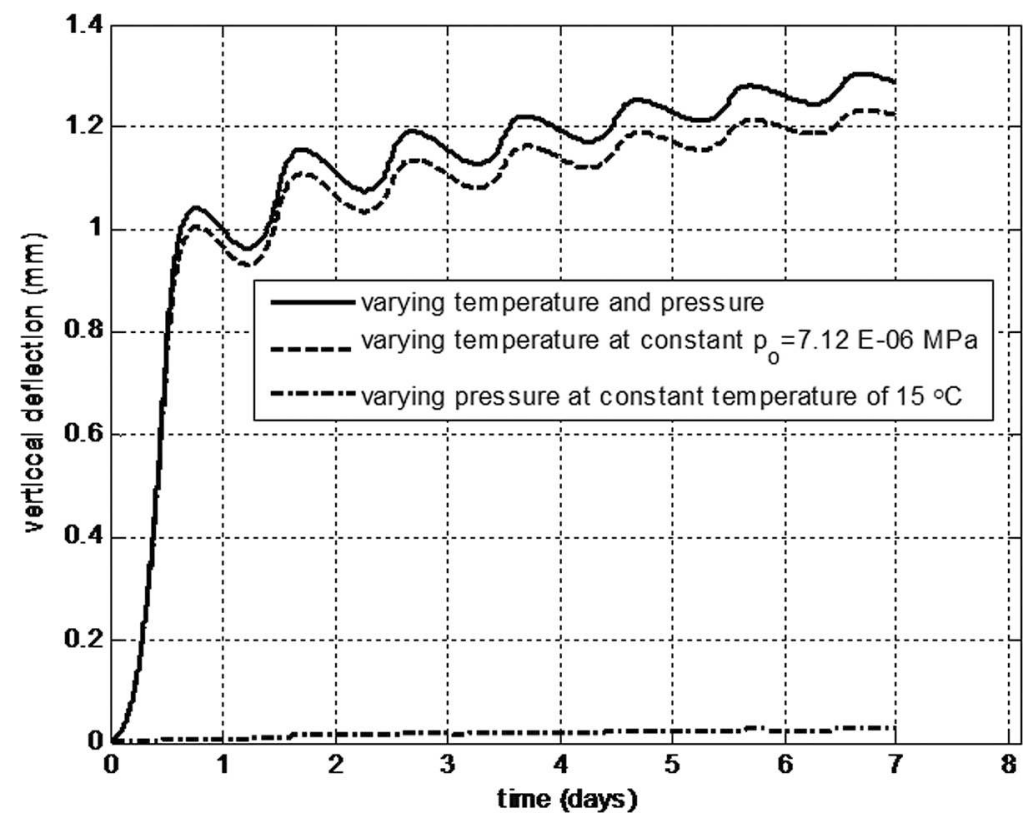

FIG. 12-Vertical deflection at the center of the plate for repeated temperature and pressure cycles for 7 days (cycles of linear increment with $12 \mathrm{~h}$ and a linear decrement within the following $12 \mathrm{~h}$ ). 
influence, as shown previously, and results in the lowest deflection of $0.02521 \mathrm{~mm}$. Moreover, Fig. 12 clearly shows that, repeated temperature and pressure cycles may well produce continuous blister growth. The blister growth tends to slow down when more cycles are applied. This corresponds to observations in practice as shown Fig. 6(a).

\section{Conclusion}

The time-dependent vertical deflection in MA blisters depends on three factors: material characterization of the model, temperature of the MA at the time of loading, and the rate at which the load is applied to the material. It was found that vertical deflection of MA is much more depending on the rate of the applied temperature than on the applied pressure. The 12-h simulation showed that, slower applied uniformly distributed pressure and temperature produces smaller vertical deflection.

For constant pressure $\left(p_{0}=7.12 \cdot 10^{-06} \mathrm{MPa}\right)$ and fluctuating temperature, the temperature dependency of the material had a great influence on the vertical deflection of the blister. This indicates that constant gas pressure inside the blister can produce significant amount of blister growth with increasing temperature.

On the other hand, for constant temperature $\left(T=25^{\circ} \mathrm{C}\right)$ and fluctuating pressure, as shown in Fig. 11(b), the blister growth is much less than in the previous case. This is because of the fact that the MA has enough stiffness to resist pressure changes. In fact, deflection would even be less if the weight of the MA was incorporated in the simulation.

Finally, from simulation of the consecutive cycles of heating and cooling, it was noticed that the daily temperature variations have a significant influence on asphalt-pavement deflection. During the unloading process, i.e., when pressure and temperature decrease, the blister still grows at a slower rate. The simulation indicates that the blister can grow continuously under repeated loading conditions over subsequent days.

\section{References}

[1] EN 13108-6, 2008, "Bitumenious Mixtures-Material Specification- Part 6: Mastic Asphalt," European Standard, VSS, Zurich.

[2] Partl, M. N. and Hean, S., "Practical Aspects of Interaction Between Mastic Asphalt and Waterproofing System in Bridge and Tunnel Construction," Proceedings of the Fourth European Symposium on Performance of Bituminous and Hydraulic Materials in Pavements, Nottingham, United Kingdom, 11 and 12 April, 2002, Balkema, Lisse, The Netherlands, 2002, pp. 58-61.

[3] Partl, M. N., Deterioration Mechanisms in Polymer-Modified Bitumen's Water Proofing Membranes Sheets During Torching, Swiss Federal Laboratories for Material Science and Technology, Duebendorf, Switzerland, 2004, pp. 12-16.

[4] Rosenberg, J., 2000, “Thin Pavements with Synthetic Binder Used in Denmark," Asphalt De Danish Road Institute, pp. 5-9.

[5] Croll, J. G. A., Thermal Buckling of Pavement Slabs, The Institution of Civil Engineers, London, 2005, Vol. 158, pp. 115-126.

[6] Alison, M., Robert, B., and Ralph, P., "Blistering in Build-up Roofs: A Review," The Fourth International Symposium on Roofing Technology, Gaithersburg, MD, Sept. 17-19, 1999, National Roofing Contractors Association, Rosemont, IL, 1999.

[7] Abaqus 6.9 User Documentation Collection, version 6.91, Dessault Systems, 2009.

[8] Timoshenko, S. and Woinowsky-Krieger, S., Theory of Plates and Shells, second ed., McGraw-Hill, New York, 1959, pp. 51-78.

[9] Reddy, J. N., Shear Deformable Beams and Plates, first ed, Elsevier, New York, 2000, pp. $11-37$.

[10] Fini, E. H., Al-Qadi, I. L., Masson, J. F., and McGhee, K. K., 2001, "Interfacial Fracture Energy: An Indicator of the Adhesion of Bituminous Material Adhesion," Electron. J. Assoc. Asph. Paving Technol., Vol. 77, pp. 827-850.

[11] Michalski, C., "Modellvorstellung Zur Deutung Des Blasewachstums Im Gussaphalt Und Anderen Thermoviskosen Stoffen Fur Den Strassenbau," Mitteilungen aus dem Fachgebiet Konstruktiver 
Strassenbau im Institut für Verkehrswirtschaft, Straßenwesen und Städtebau der Universitat Hannover, Alexander, G., Ed., Institut für Verkehrswirtschaft Straßenwesen und Städtebau der Universität Hannover, Appelstr. 9A, D-3000 Hannover, 1992.

[12] Rogosch, N., "Zur Blasenbildung in Thermoviskosen Stoffen Unter Berücksichtigung Rheologischer Materialkennwerte Und Geometrischer Randbedingungen," Mitteilungen aus dem Fachgebiet Konstruktiver Strassenbau im Institut für Verkehrswirtschaft, Straßenwesen und Städtebau der Universitat Hannover, Alexander, G., Ed., Institut für Verkehrswirtschaft Straßenwesen und Städtebau der Universität Hannover, Appelstr. 9A, D-3000 Hannover, 1994.

[13] Galliot, C. and Luchsinger, R. H., 2011, "Uniaxial and Biaxial Mechanical Properties of ETFE Foils," Polym. Test., Vol. 30, pp. 356-365.

[14] Di Benedetto, H. D., Partl, M. N., Franken, L., and De La Roche, C., 2001, "Stiffness Testing for Bituminous Mixtures," RILEM TC 182-PEB Performance Testing and Evaluation of Bituminous Materials, 2001, pp. 66-70.

[15] Christensen, D. W. and Bonaquist, R. F., 2004, "Evaluation of Indirect Tensile Test Procedures for Low-Temperature Performance of Hot Mix Asphalt," National Cooperative Highway Reasearch Program, Report No. 530, Eileen, P. D. and Eileen, M. C., Eds., Transportation Research Board of the National Academies, Washington, D.C, 2004, pp. 11-15.

[16] Huang, Y. H., Pavement Analysis and Design, second ed, Pearson Education, Upper Saddle River, NJ, 1993, pp. 328-329.

[17] Tschoegl, N. W., Wolfgang, G. K., and Igor, E., "Poisson's Ratio in Linear Viscoelasticity: A Critical Review," Mechanics of Time-Dependent Materials, Kluwer Acadamic, New York, 2002, Vol. 6, pp. $3-51$.

[18] Witczak, M. W., "Modification and Re-Calibration Superpave Thermal Cracking Model," Final Document to Transportation Research Board, Reynaldo, R., Dennis, R. H., and William, G. B., Eds., Arizona State University, Mesa, AZ, 2000, pp. 80-97.

[19] Findlay, W. N., James, S. L., and Onaran, K., Creep and Relaxation of Nonlinear Viscoelastic Materials, second ed, Dover, Mineola, NY, 1976, pp. 50-130.

[20] Shaopeng, W., Hong, W., and Mingyu, C., 2009, "Analysis of High Temperature Fluctuations on Asphalt Pavement of Cement Concrete Bridge," J. Test. Eval., Vol. 37, pp. 1-4.

[21] Partl, M. N., Remy, G., and Hean, S., "Belagsschäden Infolge Blasenbildung Auf Einer Neuen Hängebrücke in Hongkong," Nachhaltige Material-und Systemtechnik, Walter, M. and Kurt, S., eds.,Swiss Federal Laboratories for Material Science and Technology, Dubendorf und St. Gallen, Switzerland, 2001. 